\title{
Factors Affecting Under-Five Mortality in Ethiopia: A Multilevel Negative Binomial Model
}

This article was published in the following Dove Press journal:

Pediatric Health, Medicine and Therapeutics

\section{Bisrat Misganew Geremew Kassahun Alemu Gelaye (D) Alemakef Wagnew Melesse (D) Temesgen Yihunie Akalu (D) Adhanom Gebreegziabher Baraki (D)}

Department of Epidemiology and Biostatistics, Institute of Public Health, College of Medicine and Health Sciences, University of Gondar, Gondar, Ethiopia

Correspondence: Temesgen Yihunie Akalu

University of Gondar, Gondar 196,

Ethiopia

Tel +251929390709

Email temesgenyihunie@gmail.com
Purpose: Even though remarkable declines in under-five mortality rates noticed globally, nearly 5.6 million children still die annually before celebrating their fifth birthday. The 2016 Ethiopian Demographic and Health Survey (EDHS) report revealed that 67 children per 1000 live births died before the fifth birthday. This study aimed at determining factors affecting under-five mortality in Ethiopia using EDHS, 2016.

Materials and Methods: The data were retrieved from the EDHS 2016, and a total weighted number of 11,023 under-five children were included. Descriptive statistics were reported using tables, graphs, and texts. A multilevel negative binomial regression model was fitted, and adjusted incidence rate (ARR) with a 95\% confidence interval (CI) and a p-value $<0.05$ were reported. The deviance test was used to check the goodness of fit.

Results: Mother attained higher education ( $\mathrm{ARR}=0.25,95 \% \mathrm{CI}: 0.10-0.66)$, female-headed household (ARR $=1.32,95 \%$ CI: $1.05-1.66$ ), age of household head (AIRR $=1.07,95 \% \mathrm{CI}$ : $1.03,1.11$ ), preceding birth interval $\geq 48$ months ( $A R R=0.51,95 \% \mathrm{CI}: 0.42-0.61$ ), child who had history of diarrhea ( $\mathrm{ARR}=1.23,95 \% \mathrm{CI}: 1.08-1.41$ ), multiple birth type (ARR=1.80, 95\% CI: 1.34-2.42), mothers who delivered in health facility (ARR $=0.86,95 \% \mathrm{CI}$ : $0.73,0.94)$, residents of Addis Ababa (ARR $=0.52,95 \% \mathrm{CI}: 0.28-0.98)$, and Amhara region $(\mathrm{ARR}=1.43,95 \% \mathrm{CI}: 1.09,1.88)$ were statistically significant with the number of under-five mortality.

Conclusion: In this study, under-five mortality remains a public health problem in Ethiopia. Educational status of the mother, women delivered at health institution, preceding birth interval 24-35 and $\geq 48$, and residents of Addis Ababa reduced the incidence of under-five mortality. On the other hand, being a female household head, age of mother at first giving birth, being employed, having multiple births, and childhood diarrhea were associated with a higher incidence of under-five mortality. This finding suggests that enhancing opportunities to female education, addressing regional disparities, and encouraging mothers to deliver at health institutions will help to reduce the burden of under-five mortality.

Keywords: under-five mortality, negative binomial, multilevel analysis, Ethiopia

\section{Introduction}

Approximately 9.7 million infants and children died before their fifth birthday with large variations across regions and countries. ${ }^{1}$ Globally, under-five deaths have declined from more than 12 to 7.6 million since 1990 to 2010. Even though underfive mortality rate has declined by $35 \%$, children in developing countries are nearly 8 folds higher rate of dying compared to children in rich countries. ${ }^{2}$

Sub-Saharan Africa (SSA) is one of the most affected regions by childhood mortality. A report showed that more than 10.5 million children died each year and approximately about 4.4 million deaths occur in SSA. ${ }^{3}$ Even though different health 
intervention measures implemented, under-five mortality rate is the highest in Ethiopia ${ }^{4}$ and one in 11 Ethiopian children or 88 per 1000 live births dies before the fifth birthday. $^{5}$

Despite there is a reduction in under-five mortality, still many children have died before their fifth birthday in Ethiopia. Therefore, this study was aimed at determining both individual and community-level factors of under-five mortality in Ethiopia.

\section{Materials and Methods}

\section{Study Design, Area and Period}

A population-based cross-sectional study was employed from January 18 to June 27, 2016. Ethiopia is located in the Eastern tip of Africa and bordered by Eritrea to the North, Djibouti, and Somalia to the East, Sudan and South Sudan to the West, and Kenya to the South. It is the second-most populous nation in Africa, with over 100 million populations (CSA, 2012). The country covers 1.1 million square kilometers $(\mathrm{Km})$ and has a great geographical diversity, which ranges from 4550 meters (m) above sea level down to the Afar depression to $110 \mathrm{~m}$ below sea level. Administratively, it is divided into nine regions and two city administrations subdivided into 68 zones, 817 districts, and 16,253 kebeles (lowest administrative unit in the country).

\section{Population and Sample}

The EDHS 2016 sample was selected using a two-stage stratified cluster sampling technique. Each region was stratified into urban and rural areas, yielding 21 sampling strata and enumeration areas (EAs) were selected independently in each stratum. In 2016 EDHS the Ethiopia Population and Housing Census (PHC) was used as a sampling frame, which was conducted in 2007 by the Ethiopia Central Statistical Agency. The census frame was a complete list of 84,915 EAs, a geographic area covering on average 181 households. $^{6}$

In the first stage, 645 clusters (202 urban and 443 rural) were selected. In the second stage, a fixed number of 28 households per cluster were selected. Finally, 15,683 women age 15-49 in 16,650 households from 645 clusters were selected. A total of 10,641 (weighted 11,023) women were interviewed to provide information of their underfive child. ${ }^{6}$

\section{Variables of the Study}

The number of under-five children death was defined as the death of child less than 60 months within five years preceding the survey. Both individual and communitylevel factors were assessed. Individual-level factors include sex, age of mother, age of mother at first birth, marital status, preceding birth interval, birth order, size of the child, number of children, media exposure, education level of the mother, mothers' occupation, partner's occupation, economic status, religion, diarrhea status, contraceptive method use, delivery status, place of delivery, type of birth, and immunization coverage. Whereas, community-level factors include a source of water supply, place of residence, region, community poverty level, community immunization status, and availability of toilet facility.

\section{Data Collection Tools and Procedures}

A structured and pre-tested questionnaire was used to collect the data. Tablet computers were used to record responses during the interviews and the tablets were equipped with Bluetooth technology to enable remote electronic transfer of files. ${ }^{6}$ Due to the non-proportional allocation of the sample across the regions, sampling weights were used to ensure the representativeness of the finding. The sampling weights for under-five mortality are calculated similarly, although the normalization of the under-five mortality weights is different. The individual under-five mortality weights are normalized at the national level for women.

\section{Data Processing and Analysis}

Initially, data were extracted from the women's data set. Then coding and recoding were done. Summary statistics and cross-tabulation were performed to describe the study population. STATA version 14 was used for analysis. In EDHS, women within a cluster are more likely similar than women from other clusters. This indicates the use of traditional models may not be appropriate. Hence, a model that accounts for the cluster effect should be considered. A multilevel or hierarchical modeling explicitly accounts for the clustering of the units of analysis, individuals nested within groups. Since the outcome variable is count, Poisson regression is used as a standard model for analyzing it. However, the observation should be independent over time and the mean and the variance should be equal. Furthermore, an overdispersion test was performed 
to evaluate the adequacy of the negative binomial model over the Poisson regression model.

In this study, the variance was greater than the mean, it indicates an overdispersion. Hence, the negative binomial model is preferred over the poison model. Besides, the number of zeros was also checked to determine whether the zero-inflated poison model (ZIP) or the zero-inflated negative binomial model (ZINB) would be chosen. In this study, four models were constructed to estimate the underfive mortality in Ethiopia per woman under the consideration of EA variation. The first model was empty (a model without any explanatory variables) is used to assess the extent of the cluster variation on the Variance partition coefficient (VPC) or Intra-class correlation (ICC). The second model adjusted for the individual-level variables, the third model adjusted for community-level variables while the fourth model adjusted for both the individual and community-level variables simultaneously. Therefore, a multilevel model was chosen over the traditional count models. Akaike information criteria (AIC), Bayesian information criteria (BIC), and log-likelihood were used to choose the best-fitted model. Hence, a model with the lowest AIC and BIC and the highest loglikelihood was used as a best-fitted model.

A P-value of $<0.05$ was used to define the statistical significance of independent variables. The adjusted incidence rate (AIR) with corresponding 95\% confidence intervals (CIs) was calculated. ICC, Median Rate Ratio (MRR), and Proportional Change in Variance (PCV) statistics were calculated to measure the variation among clusters. ICC was used to explain cluster variation while MRR is a measure of unexplained cluster heterogeneity. ${ }^{8}$ The PCV measures the total variation attributed by individual-level factors and area-level factors in the multilevel model.

\section{Results}

\section{Characteristics of the Study Participants}

Of all, 9219 (83.63\%) of respondents were from Oromia, Amhara, and SNNP. A majority, $88.9 \%$ of study subjects were from rural areas. Nearly one-third of respondents were in the age group between 25-29 years. Nearly twothirds, $66.08 \%$ of mothers had no formal education. The poorest wealth quintile comprises nearly one-fourth $(23.92 \%)$ of the total respondents. Regarding media exposure, 7376 (66.91\%) of mothers had no media exposure. Eight thousand one hundred thirty-one (73.76\%) of mothers/caregivers delivered at home. A total of 7621 $(69.13 \%)$ of children had incomplete immunization status. Only $7.46 \%$ of the households have improved latrine while $10.36 \%$ used piped water as a source of drinking water. Nearly $70 \%$ of mothers/caregivers had no under-five death in their lifetime. On the other hand, 3.43\% of them experienced 3 or more deaths (Table 1).

\section{Model Compressions of Count Data Analysis}

Different models (Poisson, negative binomial, zeroinflated Poisson, zero-inflated negative binomial, multilevel Poisson, and multilevel negative binomial) were computed. Accordingly, the multilevel negative binomial model had the smallest LL, AIC, BIC, and deviance values. Therefore, the multilevel negative binomial regression model was the best fit for the data (Table 2).

The variance of the random part with its standard deviation was 0.23 for the final fitted model. Intra-class correlation showed that $12 \%$ variability was explained by the full model. This tells us the use of the multilevel model is more appropriate than the usual models. The Deviance test was decreasing across model one to model 4. This indicates the 4th model (model with the lowest deviance) was the best-fitted model (Table 3).

\section{Analysis of Multilevel Negative Binomial Regression Model}

Mother's education, sex of household head, age of household head, partner's occupation, types of birth, place of delivery, a child with diarrhea, birth interval, and regions had a significant association to under-five mortality in the final model. The risk of under-five mortality among primary, secondary, and higher education levels of mothers was decreased by $45 \%$ $(\mathrm{ARR}=0.55,95 \% \mathrm{CI}: 0.45-0.67), 60 \% \quad(\mathrm{ARR}=0.4,95 \%$ CI: $0.24-0.67)$, and $75 \%$ (ARR $=0.25,95 \%$ CI: 0.10 0.66), respectively, compared with uneducated. Being a female-headed household increase the risk of experiencing under-five mortality by $32 \%(\mathrm{ARR}=1.32,95 \%$ CI: 10.5-1.66).

History of diarrhea was increased the incidence of under-five mortality by $23 \%$ (ARR $=1.23,95 \%$ CI: 1.08 1.41). Besides, multiple birth type of child was $80 \%$ increase the risk of under-five mortality compared with 
Table I Weighted Socio-Demographic and Economic Characteristics of Respondents EDHS $2016(\mathrm{~N}=11,023)$

\begin{tabular}{|c|c|c|}
\hline Variables & Frequency & Percentages (\%) \\
\hline \multicolumn{3}{|l|}{ Region } \\
\hline Tigray & 716 & 6.49 \\
\hline Afar & 114 & 1.03 \\
\hline Amhara & 2072 & 18.79 \\
\hline Oromia & 4851 & 44.01 \\
\hline Somalia & 508 & 4.61 \\
\hline Benishangul & 122 & 1.11 \\
\hline SNNP & 2296 & 20.83 \\
\hline Gambella & 27 & 0.24 \\
\hline Harari & 26 & 0.24 \\
\hline Addis Ababa & 244 & 2.21 \\
\hline Dire Dawa & 47 & 0.44 \\
\hline \multicolumn{3}{|l|}{ Residence } \\
\hline Urban & 1216 & 11.03 \\
\hline Rural & 9807 & 88.97 \\
\hline \multicolumn{3}{|l|}{ Mother's age } \\
\hline $15-19$ & 378 & 3.43 \\
\hline $20-24$ & 2068 & 18.76 \\
\hline $25-29$ & 3353 & 30.42 \\
\hline $30-34$ & 2489 & 22.58 \\
\hline $35-39$ & 1772 & 16.08 \\
\hline $40-44$ & 723 & 6.56 \\
\hline $45-49$ & 240 & 2.17 \\
\hline \multicolumn{3}{|l|}{ Mother's educational level } \\
\hline Illiterate & 7284 & 66.08 \\
\hline Elementary & 2951 & 26.77 \\
\hline Secondary & 514 & 4.66 \\
\hline Tertiary & 274 & 2.49 \\
\hline \multicolumn{3}{|l|}{ Wealth index } \\
\hline Poorest & 2636 & 23.92 \\
\hline Poor & 2520 & 22.86 \\
\hline Middle & 2279 & 20.68 \\
\hline Richer & 1999 & 18.13 \\
\hline Richest & 1588 & $|4.4|$ \\
\hline \multicolumn{3}{|l|}{ Media exposure } \\
\hline No & 7376 & 66.91 \\
\hline Yes & 3647 & 33.09 \\
\hline \multicolumn{3}{|l|}{ Age at first birth } \\
\hline Less than 15 & 687 & 6.24 \\
\hline $15-24$ & 7405 & 67.18 \\
\hline Above 24 & 2931 & 26.58 \\
\hline \multicolumn{3}{|l|}{ Types of birth } \\
\hline Single & 10,730 & 97.35 \\
\hline Multiple & 293 & 2.65 \\
\hline \multicolumn{3}{|l|}{ Marital status } \\
\hline Unmarried & 684 & 6.2 \\
\hline Married & 10,339 & 93.8 \\
\hline
\end{tabular}

(Continued)
Table I (Continued).

\begin{tabular}{|c|c|c|}
\hline Variables & Frequency & Percentages (\%) \\
\hline \multicolumn{3}{|l|}{ Place of delivery } \\
\hline Home & 8131 & 73.76 \\
\hline Institute & 2892 & 26.24 \\
\hline \multicolumn{3}{|l|}{ Religion } \\
\hline Christian & 6101 & 55.35 \\
\hline Muslim & 4561 & 41.38 \\
\hline Others* & 361 & 3.27 \\
\hline \multicolumn{3}{|l|}{ Diarrhea } \\
\hline No & 8951 & 81.2 \\
\hline Yes & 2072 & 18.8 \\
\hline \multicolumn{3}{|l|}{ Sex of household head } \\
\hline Male & 9494 & 86.13 \\
\hline Female & 1529 & 13.87 \\
\hline \multicolumn{3}{|l|}{ Sex of child } \\
\hline Male & 5725 & 51.94 \\
\hline Female & 5298 & 48.06 \\
\hline \multicolumn{3}{|l|}{ Source of water } \\
\hline Piped water & 2931 & 26.58 \\
\hline Other improved & 3185 & 28.9 \\
\hline Un improved & 4907 & 44.53 \\
\hline \multicolumn{3}{|l|}{ Number of under-five children } \\
\hline One & 4079 & 37.0 \\
\hline Two & 4779 & 43.36 \\
\hline Three & 1578 & 14.32 \\
\hline Four and above & 587 & 5.32 \\
\hline \multicolumn{3}{|l|}{ Size of a child at birth } \\
\hline Very large & 1957 & 17.75 \\
\hline Larger than average & 1528 & 13.87 \\
\hline Average & 4580 & 41.55 \\
\hline Smaller than average & 2958 & 26.83 \\
\hline \multicolumn{3}{|l|}{ Immunization status } \\
\hline Incomplete & 7621 & 69.13 \\
\hline Complete & 3402 & 30.87 \\
\hline \multicolumn{3}{|l|}{$\begin{array}{l}\text { Mothers with number of under- } \\
\text { five children }\end{array}$} \\
\hline No death & 7659 & 69.48 \\
\hline One child death & 2289 & 20.76 \\
\hline Two child death & 697 & 6.32 \\
\hline Three child death & 236 & 2.14 \\
\hline$\geq 4$ child death & 142 & 1.29 \\
\hline
\end{tabular}

Note: *Protestant and catholic.

a single birth type (ARR $=1.80,95 \%$ CI: $1.34-2.42)$. On the other hand, mothers delivered at health facilities decreased the incidence of child death by $14 \%$ compared to home delivery (ARR $=0.86,95 \%$ CI: 0.73 , 0.94) and living in Addis Ababa decreases the incidence 
Table 2 Model Comparison of Under-Five Children in Ethiopia, EDHS 2016

\begin{tabular}{|l|l|l|l|l|l|}
\hline Model & Observation & LL & AIC & BIC & Deviance \\
\hline Poisson & $10,64 \mid$ & -6755.04 & $13,572.09$ & $13,794.80$ & $13,510.08$ \\
Negative binomial & $10,64 \mid$ & -6654.96 & $13,373.93$ & $13,603.82$ & $13,309.92$ \\
Zero inflated Poisson & $10,64 \mid$ & -6572.56 & $13,265.11$ & $13,696.16$ & $13,145.12$ \\
Zero inflated negative binomial & $10,64 \mid$ & -6556.61 & $13,235.23$ & $13,673.46$ & $13,1 \mid 3.22$ \\
Multilevel Poisson & $10,64 \mid$ & -6587.16 & $\mid 3,238.32$ & $13,468.2 \mid$ & $13,174.32$ \\
Multilevel negative binomial & $10,64 \mid$ & $-486.2 \mid$ & $13,183.11$ & $13,420.18$ & $12,972.42$ \\
\hline
\end{tabular}

Table 3 Random Parameter Estimates Among Under-Five Children, EDHS, 2016

\begin{tabular}{|l|l|l|l|l|}
\hline $\begin{array}{l}\text { Measure of } \\
\text { Variation }\end{array}$ & Model I & Model 2 & Model 3 & Model 4 \\
\hline $\begin{array}{l}\text { Variance (SE) } \\
\text { Explained } \\
\text { variation }\end{array}$ & $\begin{array}{l}0.456(0.675) \\
\text { ICC \% }\end{array}$ & $\begin{array}{l}0.254(0.504) \\
18.3\end{array}$ & $\begin{array}{l}0.28(0.53) \\
21.3\end{array}$ & $\begin{array}{l}0.23(0.479) \\
\text { MRR }\end{array}$ \\
$\begin{array}{l}\text { DIC (-2log } \\
\text { likelihood) }\end{array}$ & 1.90 & 1.61 & 1.66 & 1.58 \\
\hline
\end{tabular}

of under-five mortality by $48 \%$ ( $\mathrm{ARR}=0.52,95 \% \mathrm{CI}$ : 0.28-0.98) compared with Tigray region. The risk of under-five mortality was increased by $58 \%$ if we moved from the Tigray region to other regions except for Addis Ababa (Table 4).

\section{Discussion}

This study showed individual- and community-level determinants of under-five mortality in Ethiopia. A multilevel negative binomial model was used to identify possible factors of under-five mortality. According to 2016 EDHS, nearly one-third of mothers/caregivers lost a minimum of one child within the study period. In this study mothers' education, female household head, age of household head, occupation of mothers, having multiple births, place of delivery, preceding birth interval, child with diarrhea, and regions significantly affect under-five mortality.

Maternal education was reduced the risk of under-five mortality. This finding was supported by studies from Zimbabwe and Indonesia, respectively. ${ }^{8,9}$ Moreover, findings from Gilgel Gibe, Ethiopia showed that children born from illiterate mothers were at a higher risk of under-five mortality. ${ }^{10}$ Besides, findings from Ghana, ${ }^{11}$ Ethiopia, ${ }^{12}$ Columbia, ${ }^{13}$ and Pakistan $^{14}$ showed that educating mothers was significantly reduced child mortality. The reason could be educated mothers will have a better knowledge and good practice in basic health services including immunization, disease treatment, preventive care, hygiene, and nutrition. Moreover, a study from India showed that educating females have a lower incidence of under-five mortality 15). This finding illustrates that educating women is a powerful strategy to combat under-five mortality.

The female household head was associated with an increase in the incidence of under-five mortality. This finding was in agreement with a study done in Uganda ${ }^{16}$ and Indonesia. ${ }^{9}$ This is due to female-headed households are at high risk of food insecurity and more likely to be not fully immunized ${ }^{17}$ hence, prone to vaccine-preventable disease and death. This indicates that female-headed households will make difficulties to made decisions on child health and well busy for other responsibilities in the house and social cases. A unit increase in the age of household head increased the risk of under-five mortality. This could be as age increased the probability of giving child care will decrease. Besides,

Partners who are working are at a higher incidence of under-five mortality than non-working parents. However, it is in contrast with a study conducted in Nigeria ${ }^{18}$ which showed that being employment reduced the risk of underfive mortality. Employment generates income that aids the mother/caregiver to seek health care at any time when the child was sick. On the other hand, being employed would decrease prompt visits to health facilities while the child was sick. This could result in a delay in seeking health care since the partner could be busy. Therefore, the finding suggests that there is a need for further research to overcome confusion.

The preceding birth interval has an inverse relationship with under-five mortality. Children born after 24-35, 36-47, and more than 47 months of the preceding birth intervals had a lower risk of child mortality compared to 
Table 4 Multilevel Negative Binomial Regression Analysis of Individual and Community-Level Factors Associated with the Number of Under-Five Child Death in Ethiopia, EDHS $2016(\mathrm{~N}=11,023)$

\begin{tabular}{|c|c|c|c|c|}
\hline & Null & Individual-Level & Community-Level & Adjusted by Both \\
\hline Number of deaths per mothers & & Adjusted IRR $95 \% \mathrm{Cl}$ & Adjusted IRR $95 \% \mathrm{Cl}$ & Adjusted IRR $95 \% \mathrm{Cl}$ \\
\hline \multicolumn{5}{|l|}{ Mother's educational level } \\
\hline Illiterate & & I & & 1 \\
\hline Primary & & $0.54(0.45,0.66)$ & & $0.55(0.45,0.67)$ \\
\hline Secondary & & $0.39(0.23,0.65)$ & & $0.40(0.24,0.67)$ \\
\hline Higher & & $0.24(0.10,0.62)$ & & $0.25(0.10,0.66)$ \\
\hline Age of respondents at first birth & & $1.08(1.03,1.10)$ & & $1.07(1.03,1.11)$ \\
\hline \multicolumn{5}{|l|}{ Sex of household head } \\
\hline Male & & I & & 1 \\
\hline Female & & $1.36(1.09,1.70)$ & & $1.32(1.05,1.66)$ \\
\hline Age of household head & & $1.02(1.02,1.03)$ & & $1.02(1.02,1.03)$ \\
\hline \multicolumn{5}{|l|}{ Mother's working status } \\
\hline Not working & & I & & 1 \\
\hline Working & & $1.19(1.00,1.41)$ & & $1.16(0.98,1.38)$ \\
\hline \multicolumn{5}{|l|}{ Partners occupation } \\
\hline Not working & & 1 & & 1 \\
\hline Working & & $1.18(0.97,1.42)$ & & $1.22(1.01,1.47)$ \\
\hline \multicolumn{5}{|l|}{ Type of birth } \\
\hline Single & & 1 & & 1 \\
\hline Multiple & & $\mathrm{I} .74(\mathrm{I} .3 \mathrm{I}, 2.32)$ & & $1.80(1.34,2.42)$ \\
\hline \multicolumn{5}{|l|}{ Cesarean section delivery } \\
\hline No & & 1 & & 1 \\
\hline Yes & & I.32(0.72, 2.40) & & $1.72(0.72,2.52)$ \\
\hline \multicolumn{5}{|l|}{ Marital status } \\
\hline Unmarried & & 1 & & 1 \\
\hline Married & & $1.52(1.06,2.19)$ & & $1.39(0.96,2.03)$ \\
\hline \multicolumn{5}{|l|}{ Place of delivery } \\
\hline Home & & 1 & & 1 \\
\hline Institutional & & $0.87(0.74,1.02)$ & & $0.86(0.73,0.94)$ \\
\hline \multicolumn{5}{|l|}{ Preceding birth interval } \\
\hline$<24$ & & 1 & & 1 \\
\hline $24-35$ & & $0.81(0.68,0.96)$ & & $0.81(0.68,0.96)$ \\
\hline $36-47$ & & $0.87(0.72,1.05)$ & & $0.84(0.69,1.02)$ \\
\hline$\geq 48$ & & $0.52(0.43,0.63)$ & & $0.51(0.42,0.61)$ \\
\hline \multicolumn{5}{|l|}{ Child diarrhea status } \\
\hline No & & I & & 1 \\
\hline Yes & & $1.19(1.04,1.37)$ & & $1.23(1.08,1.41)$ \\
\hline \multicolumn{5}{|l|}{ Media exposure } \\
\hline Unexposed & & I & & 1 \\
\hline Exposed & & $0.91(0.76,1.09)$ & & $0.92(0.76,1.12)$ \\
\hline \multicolumn{5}{|l|}{ Immunization coverage } \\
\hline Complete & & 1 & & 1 \\
\hline Incomplete & & $1.17(0.96,1.42)$ & & I.I2(0.91, I.39) \\
\hline
\end{tabular}

(Continued) 
Table 4 (Continued).

\begin{tabular}{|c|c|c|c|c|}
\hline & Null & Individual-Level & Community-Level & Adjusted by Both \\
\hline \multicolumn{5}{|c|}{ Household Wealth Index } \\
\hline Poorest & & I & & I \\
\hline Poor & & $1.15(0.85,1.55)$ & & $\mathrm{I} .15(0.85,1.57)$ \\
\hline Middle & & $1.18(0.92,1.53)$ & & $1.20(0.91,1.60)$ \\
\hline Richer & & $1.27(0.94,1.71)$ & & $1.20(0.87,1.64)$ \\
\hline Richest & & $1.17(0.70,1.96)$ & & $1.00(0.50,2.00)$ \\
\hline \multicolumn{5}{|l|}{ Source of water } \\
\hline Piped water & & 1 & & 1 \\
\hline Other improved water & & $1.05(0.81,1.35)$ & & $1.03(0.78,1.36)$ \\
\hline unimproved water & & $\mathrm{I} .05(0.84,1.3 \mathrm{I})$ & & $1.03(0.83,1.29)$ \\
\hline \multicolumn{5}{|l|}{ Place residence } \\
\hline Urban & & & & 1 \\
\hline Rural & & & & $0.86(0.48,1.55)$ \\
\hline \multicolumn{5}{|l|}{ Region } \\
\hline Tigray & & & 1 & 1 \\
\hline Afar & & & $1.95(1.45,2.63)$ & $1.62(1.14,2.29)$ \\
\hline Amhara & & & $1.47(1.13,1.92)$ & $1.43(1.09,1.88)$ \\
\hline Oromia & & & $1.25(0.97,1.60)$ & $1.08(0.82,1.35)$ \\
\hline Somali & & & $1.47(1.12,1.92)$ & I.3I(0.95 I.80) \\
\hline Benishangul & & & $1.58(1.18,2.10)$ & $1.47(1.10,1.97)$ \\
\hline SNNPA & & & $1.46(1.11,1.91)$ & $1.48(1.13,1.93)$ \\
\hline Gambella & & & $1.07(0.82,1.40)$ & $1.39(1.00,1.93)$ \\
\hline Harari & & & $1.18(0.85,1.64)$ & $1.17(0.84,1.64)$ \\
\hline Addis Ababa & & & $0.45(0.25,0.80)$ & $0.52(0.28,0.98)$ \\
\hline Dire Dawa & & & $1.61(1.20,2.16)$ & $1.50(1.13,2.00)$ \\
\hline \multicolumn{5}{|l|}{ Latrine facility type } \\
\hline Improved & & I & & 1 \\
\hline Un improved & & $1.12(0.82,1.53)$ & & $1.10(0.80,1.51)$ \\
\hline \multicolumn{5}{|c|}{ Community poverty level } \\
\hline Low & & & I & 1 \\
\hline High & & & $1.01(0.82,1.24)$ & $1.9(0.52,2.31)$ \\
\hline \multicolumn{5}{|c|}{ Community water source } \\
\hline Improved & & & 1 & 1 \\
\hline Unimproved water & & & $1.34(1.06,1.70)$ & $0.97(0.75,1.26)$ \\
\hline \multicolumn{5}{|c|}{ Community immunization } \\
\hline Complete & & & 1 & 1 \\
\hline Incomplete & & & I.I I $(0.85,1.44)$ & $0.98(0.86,2.51)$ \\
\hline \multicolumn{5}{|c|}{ Community media exposure } \\
\hline Unexposed & & & I & 1 \\
\hline Exposed & & & $0.99(0.78,1.25)$ & $1.09(0.87,1.36)$ \\
\hline
\end{tabular}

children born less than 24 months. This finding was consistent with a study conducted in Ethiopia, ${ }^{19} \mathrm{Kenya}^{20}$ and India. $^{21}$ This could be shorter birth intervals are associated with maternal nutritional reduction and the child would prone to malnutrition and it will further increase the risk of death.
The incidence of under-five mortality was higher among children with diarrheal disease. This finding was in line with a study done in Nigeria. ${ }^{22}$ This is because diarrheal diseases cause water and electrolyte loss that resulted in dehydration and electronic imbalance that further resulted to death. ${ }^{23}$ The study also revealed 
that multiple births were contributed to a high risk of under-five mortality. The result was supported by studies from Ethiopia, ${ }^{24}$ Cambodia, ${ }^{25}$ and Ghana. ${ }^{26}$ This could be multiple births are at higher risk of fetal and neonatal complications and usually needs special intervention which is costly and unaffordable. ${ }^{27}$ Therefore, enhanced and comprehensive health-care service is recommended to mothers/caregivers during pregnancy, delivery and the postpartum period to minimize the risk of under-five mortality.

In this study, an increase in the age of mothers/caregivers was associated with an increase in the incidence of under-five mortality. A study from Columbia, ${ }^{13}$ Pakistan, ${ }^{14}$ and India $^{28}$ showed that an increase in mothers/caregivers of age by one year was associated with a decrease in under-five mortality. This could be young mothers/caregivers are incapable to tolerate pregnancy-related complications and incompetent to take proper care of children in terms of feeding and handling. The results of the multilevel negative binomial model showed that the incidence of under-five mortality was declined among mothers deliver at health institutions. This result is supported by a study done from Pakistan. ${ }^{29}$ Home delivery significantly increases under-five mortality due to high risk of postpartum complications following intrapartum. Besides, home delivery contributes to common vaccine-preventable diseases due to the absence of vaccination history of a child.

Under-five mortality was lower in Addis Ababa and higher in other regions compared with the Tigray region. This finding is in agreement with a study from Mozambique $^{30}$ which showed that the distribution of disease among regions was quite different because of difference in basic infrastructure distribution like health coverage and regional variations in economic development. Furthermore, the finding was in line with a study from Nigeria ${ }^{31}$ which showed that regional variation significantly affects underfive mortality. Therefore, this finding demonstrates that providing an equal and fair distribution of wealth and health service coverage will tailor the variation observed among different regions of Ethiopia.

The strength of this study was the incorporation of multi-center sites of the region. This could enhance the generalization of the study findings to the whole regions. Besides, the study was aimed at determining individual and community-level factors among under-five mortality in Ethiopia. Moreover, the quality of the statistical treatment used gave a more precise statistical estimate. However, this study also faces some limitations. This study might also be affected by misclassification and recall bias during the data collection. Another important limitation of the study was the actual age at death and causes of death were unknown.

This study has played an important role in determining the number of under-five mortality and factors affecting among under-five children in Ethiopia. This could be used as baseline information for researchers to conduct further prospective studies. Moreover, the study will be valuable for policymakers, decision-makers, planners, and implementers working on the field.

\section{Conclusion}

In this study, under-five mortality remains a public health problem in Ethiopia. Mothers' education being primary and above, women delivered at health institution, preceding birth interval $24-35$ and $\geq 48$, and residents of Addis Ababa have reduced the incidence of under-five mortality. On the other hand, being a female household head, age of mother at first giving birth, being employment, having multiple births, and having childhood diarrhea was associated with a higher incidence of under-five mortality. This finding suggests that enhancing opportunities to female education, addressing geographical disparities, and encouraging mothers to deliver at health institutions will help to combat the burden of under-five mortality.

\section{Abbreviations}

AIC, Akaike Information Criteria; AIRR, adjusted incidence rate ratio; $\mathrm{BIC}$, Bayesian Information Criteria; CSA, Central Statistical Agency; DHS, Demographic and Health Survey; EA, enumeration area; EDHS, Ethiopian Demographic and Health Survey; GPS, global positioning system; ICC, intra-class correlation; IGME, Inter-agency Group for Child Mortality Estimation; IMR, infant mortality rate; IRR, incidence rate ratio; LISA, local indicators of spatial association; LL, loglikelihood; MDGs, millennium development goals; NB, negative binomial; OR, odds ratio; PHC, Population and Housing Census; PR, Poisson regression; SNNP, South Nation, Nationalities and People; SA, Sub-Saharan Africa; TFR, total fertility rate; U5CD, under-five child death; U5CM, under-five child mortality; U5M, underfive mortality; U5MR, under-five mortality rate; UNICEF, United Nations International Children Emergency Fund; UNPD, United Nations Population Division; USAID, United States Agency for 
International Development; WHO, World Health Organization; ZIP, Zero Inflated Poisson.

\section{Data Sharing Statement}

Data is available on https://dhsprogram.com/data/avail able-datasets.cfm.

\section{Ethics Approval and Consent to Participate}

Permission to use the EDHS data was obtained from the Measure DHS international program. The data is publicly available and has no personal identifiers.

\section{Consent for Publication}

Not applicable.

\section{Acknowledgments}

We would like to thank the Measure DHS International Program for providing the data set.

\section{Author Contributions}

All authors made substantial contributions to conception and design, acquisition of data, or analysis and interpretation of data; took part in drafting the article or revising it critically for important intellectual content; agreed to submit to the current journal; gave final approval of the version to be published; and agree to be accountable for all aspects of the work.

\section{Funding}

No funding was obtained for this study.

\section{Disclosure}

The authors declare that they have no conflict of interest.

\section{References}

1. UNICEF.. The state of the world's children 2006: excluded and invisible: UNICEF. 2005.

2. De Onis M, Brown D, Blossner M, Borghi E. Levels and trends in child malnutrition. UNICEF-WHO-The World Bank Joint Child Malnutrition Estimates. 2012.

3. Bryce J, Boschi-Pinto C, Shibuya K, Black RE, Group WCHER. WHO estimates of the causes of death in children. Lancet. 2005;365 (9465):1147-1152. doi:10.1016/S0140-6736(05)71877-8

4. Omariba D. Family level clustering of childhood mortality in Kenya. PSC Discussion Papers Series. 2004;18(9):1.

5. Ayele DG, Zewotir TT. Childhood mortality spatial distribution in Ethiopia. J Appl Stat. 2016;43(15):2813-2828. doi:10.1080/ 02664763.2016 .1144727
6. Csace I. Ethiopia Demographic and Health Survey 2016 Addis Ababa. Ethiopia, and Rockville, maryland, USA: CSA and ICF; 2016.

7. Chaix B, Rosvall M, Merlo J. Assessment of the magnitude of geographical variations and socioeconomic contextual effects on ischaemic heart disease mortality: a multilevel survival analysis of a large Swedish cohort. J Epidemiol Community Health. 2007;61(4):349-355. doi:10.1136/jech.2006.047597

8. Kembo J, Van Ginneken JK. Determinants of infant and child mortality in Zimbabwe: results of multivariate hazard analysis. Demogr Res. 2009;21:367-384. doi:10.4054/DemRes.2009.21.13

9. Campbell AA, de Pee S, Sun K, et al. Relationship of household food insecurity to the neonatal, infant, and under-five child mortality among families in rural Indonesia. Food Nutr Bull. 2009;30 (2):112-119. doi:10.1177/156482650903000202

10. Deribew A, Tessema F, Girma B. Determinants of under-five mortality in Gilgel gibe field research center, Southwest Ethiopia. Ethiopian J Health Development. 2007;21(2):117-124. doi:10.4314/ejhd.v21i2.10038

11. Kayode GA, Adekanmbi VT, Uthman OA. Risk factors and a predictive model for under-five mortality in Nigeria: evidence from Nigeria demographic and health survey. BMC Pregnancy Childbirth. 2012;12(1):10. doi:10.1186/1471-2393-12-10

12. Ayele DG, Zewotir TT. Comparison of under-five mortality for 2000 , 2005 and 2011 surveys in Ethiopia. BMC Public Health. 2016;16:930. doi:10.1186/s12889-016-3601-0

13. Somoza JL. Illustrative analysis: infant and child mortality in Colombia. Notas De Poblacion. 1980;8:93-122.

14. Agha S. The determinants of infant mortality in Pakistan. Soc Sci Med. 2000;51(2):199-208. doi:10.1016/S0277-9536(99)00460-8

15. Mandal S, Paul P, Chouhan P. Impact of maternal education on underfive mortality of children in India: insights from the national family health survey, 2005-2006 and 2015-2016. Death Stud. 2019;1-7. doi:10.1080/07481187.2019.1692970

16. Nasejje JB, Mwambi HG, Achia TN. Understanding the determinants of under-five child mortality in Uganda including the estimation of unobserved household and community effects using both frequentist and Bayesian survival analysis approaches. BMC Public Health. 2015;15:1003.

17. Tamirat KS, Sisay MM. Full immunization coverage and its associated factors among children aged 12-23 months in Ethiopia: further analysis from the 2016 Ethiopia demographic and health survey. BMC Public Health. 2019;19(1):1019. doi:10.1186/s12889-0197356-2

18. Akinyemi JO, Solanke BL, Odimegwu CO. Maternal employment and child survival during the era of sustainable development goals: insights from proportional hazards modelling of nigeria birth history data. Ann Global Health. 2018;84(1):15-30. doi:10.29024/aogh.11

19. Jackson R, Caldwell M. Geostatistical patterns of soil heterogeneity around individual perennial plants. J Ecology. 1993;81:683-692. doi: $10.2307 / 2261666$

20. Mbugua S, Musikoyo E, Ndungi F, Sang R, Kamau-Mbuthia E. Ngotho D: determinants of diarrhea among young children under the age of five in Kenya, evidence from KDHS 2008-09. African Population Studies. 2014;28:1046-1056. doi:10.11564/28-0-556

21. Singh R, Tripathi V. Maternal factors contributing to under-five mortality at birth order 1 to 5 in India: a comprehensive multivariate study. SpringerPlus. 2013;2:284. doi:10.1186/2193-1801-2-284

22. Muoneke VU, Ibekwe RC, Nebe-Agumadu HU. Ibe BC: factors associated with mortality in under-five children with severe anemia in Ebonyi, Nigeria. Indian Pediatr. 2012;49(2):119-123. doi:10.1007/ s13312-012-0026-4

23. Ahmad MS, Wahid A, Ahmad M, Mahboob N, Mehmood R. Prevalence of electrolyte disorders among cases of diarrhea with severe dehydration and correlation of electrolyte levels with age of the patients. J College Physicians Surgeons- Pakistan. 2016;26 (5):394-398. 
24. Ezra M, Gurum E. Breastfeeding, birth intervals, and child survival: analysis of the 1997 community and family survey data in southern Ethiopia. Ethiopian J Health Development. 2002;16(1):41-51. doi:10.4314/ejhd.v16i1.9825

25. Bhutta ZA, Chopra M, Axelson H, et al. Countdown to 2015 decade report (2000-10): taking stock of maternal, newborn, and child survival. lancet. 2010;375(9730):2032-2044. doi:10.1016/S0140-6736(10)60678-2

26. Aheto JMK. Predictive model and determinants of under-five child mortality: evidence from the 2014 Ghana demographic and health survey. BMC Public Health. 2019;19(1):64. doi:10.1186/s12889-0196390-4

27. Ananth CV, Joseph KS, Demissie K, Vintzileos AM. Trends in twin preterm birth subtypes in the United States, 1989 through 2000: impact on perinatal mortality. Am J Obstet Gynecol. 2005;193(3 Pt 2):1076-1082. doi:10.1016/j.ajog.2005.06.088
28. Singh R, Tripathi V. Under-five mortality among mothers employed in agriculture: findings from a nationally representative sample. PeerJ. 2015;3:e710. doi:10.7717/peerj.710

29. Ghulam R, Rahman I, Naqvi S, Gupta S. An epidemiological study of drug abuse in an urban population of Madhya Pradesh. Indian J Psychiatry. 1996;38(3):160.

30. Macassa G, Ghilagaber G, Charsmar H, Walander A, Sundin O, Soares J. Geographic differentials in mortality of children in Mozambique: their implications for achievement of Millennium Development Goal 4. J Health Popul Nutr. 2012;30(3):331-345. doi:10.3329/jhpn.v30i3.12297

31. Adedini SA, Odimegwu C, Imasiku EN, Ononokpono DN, Ibisomi L. Regional variations in infant and child mortality in nigeria: a multilevel analysis. $J$ Biosoc Sci. 2015;47(2):165-187. doi:10.1017/S0021932013000734

\section{Publish your work in this journal}

Pediatric Health, Medicine and Therapeutics is an international, peerreviewed, open access journal publishing original research, reports, editorials, reviews and commentaries. All aspects of health maintenance, preventative measures and disease treatment interventions are addressed within the journal. Practitioners from all disciplines are invited to submit their work as well as healthcare researchers and patient support groups. The manuscript management system is completely online and includes a very quick and fair peer-review system. Visit http://www.dovepress.com/testimonials.php to read real quotes from published authors.

Submit your manuscript here: http://www.dovepress.com/pediatric-health-medicine-and-therapeutics-journal 